\title{
Assessing drought cycles in SPI time series using a Fourier analysis
}

\author{
E. E. Moreira ${ }^{1}$, D. S. Martins ${ }^{2}$, and L. S. Pereira ${ }^{3}$ \\ ${ }^{1}$ CMA - Center of Mathematics and Applications, Faculty of Sciences and Technology, Nova University of Lisbon, \\ 2829-516 Caparica, Portugal \\ ${ }^{2}$ Institute Dom Luiz, Faculty of Sciences, University of Lisbon, 1749-016 Lisbon, Portugal \\ ${ }^{3}$ LEAF, Research Center for Landscape, Environment, Agriculture and Food, Institute of Agronomy, University of Lisbon, \\ 1349-017 Lisbon, Portugal
}

Correspondence to: E. Moreira (efnm@fct.unl.pt)

Received: 28 February 2014 - Published in Nat. Hazards Earth Syst. Sci. Discuss.: 23 April 2014

Revised: 23 February 2015 - Accepted: 24 February 2015 - Published: 13 March 2015

\begin{abstract}
In this study, drought in Portugal was assessed using 74 time series of Standardized Precipitation Index (SPI) with a 12-month timescale and 66 years length. A clustering analysis on the SPI Principal Components loadings was performed in order to find regions where SPI drought characteristics are similar. A Fourier analysis was then applied to the SPI time series considering one SPI value per year relative to every month. The analysis focused on the December SPI time series grouped in each of the three identified clusters to investigate the existence of cycles that could be related to the return periods of droughts. The most frequent significant cycles in each of the three clusters were identified and analysed for December and the other months. Results for December show that drought periodicities vary among the three clusters, pointing to a 6-year cycle across the country and a 9.4-year cycle in central and southern Portugal. Both these cycles likely show the influence of the North Atlantic Oscillation (NAO) on the occurrence and severity of droughts in Portugal. Relative to other months it was observed that cycles varied according to the common occurrence of precipitation: for the rainy months - November, December and January - cycles are similar to those for December; for the dry months - May to September - where the lack of precipitation masks the occurrence of drought, the dominant cycles are of short duration and cannot be related to the NAO or other large circulation indices to explain drought variability; for the transition months - February, March, April and October - 6-year and 3-year cycles were identified, the latter being more strongly apparent in central and southern Portugal. NAO influence is again identified relative to the 6-year cycles. The short cycles are apparently associated with positive
\end{abstract}

SPI, thus with wetness, not drought. Overall, results confirm the importance of the NAO as a driving force for dry and wet periods.

\section{Introduction}

The cyclicity of climatic and Earth surface processes such as precipitation, streamflow and droughts is the object of a variety of studies aimed at better understanding their variability and identifying possible driving forces. With this objective, some studies aimed at the reconstruction of past climate series to allow a better analysis of past and present droughts. This was the case for a study used to reconstruct drought time series with historical data (1502-1899) relative to the south-eastern Mexico, that led to the discovery of cycles of several periodicities likely related to the El Niño-Southern Oscillation (ENSO) and solar activity (Mendoza et al., 2006). Another example is a study using historical data from Sicily, from 1565 to 1915 , that also identified several periodicities of droughts, particularly related to solar cycles (Piervitali and Colacino, 2001).

Studies referring to recent time series of precipitation, streamflow and drought indices are of particular interest for understanding the influences of large scale indices of atmospheric circulation on drought occurrence and severity. To assess the cyclicity of drought occurrence, various methods can be used and applied to those time series, such as various approaches to the Fourier analysis (Rodrigo et al., 2000; Yadava and Ramesh, 2007), also called spectral analysis (Bordi et al., 2004a, b; Mitra et al., 1991; Telesca et al., 2013), 
and the wavelet transform analysis (Labat, 2006; Prokoph et al., 2012; Li et al., 2013). Fourier analysis uses the Fourier decomposition of series and the periodogram device (Pollock, 1999; Bloomfield, 2000) with the aim of finding cycles within a given time series.

Research generally aims at finding a better explanation of time and space variability of the processes and relating the detected cycles with the periodicity of sea-surface anomalies, solar cycles or large-scale indices of atmospheric circulation. Studies with annual or monsoon precipitation data series often identified cycles of around 11 years which were related to solar activity cycles (Mazzarella and Palumbo, 1992; Mitra et al., 1991; Yadara and Ramesh, 2007; Chattopadhyay and Chattopadhyay, 2011). Studies on solar cycles were reported by Tsiropoula (2003) and Hathaway (2010). The cycle of solar activity is characterized by the rise and fall in the number and surface area of sunspots ranging between 9 and 13 years and averaging 11 years (Hathaway, 2010).

Streamflow periodicities could also be related to solar cycles (e.g. Prokoph et al., 2012). A streamflow study relative to Europe (Labat, 2006) has shown interannual 4- to 5-year, 14-year and multidecadal 25- and 50-year oscillations. Gómiz-Fortis et al. (2011) studied streamflow variability in the Ebro basin and found that respective oscillation have different periodicity among the sub-regions considered. Rodríguez-Puebla et al. (1999) used 50-year series of 3-month cumulated precipitation in the Iberian Peninsula and applied principal component analysis (PCA). They detected that the North Atlantic Oscillation (NAO) was the major source of interannual variability in winter precipitation and observed that the time series of precipitation and the NAO had a common peak at about 8 years while showing a significant coherence. An analysis of rainfall variability relative to southern Spain found an alternation of wet and dry periods, with various periodicities, that allowed authors to identify the NAO among the most possible causal mechanisms in the region (Rodrigo et al., 2000). The precipitation variability study by Lucero and Rodríguez (2002) stated that "the first principal component of the transformed bidecadal component of annual rainfall anomalies attains its positive (negative) peak about 3 years before the bidecadal component of NAO reaches its negative (positive) peak".

Bordi et al. (2004a) using PCA applied to SPI with 24month timescale (SPI-24) for the Elba basin and Sicily found significant peaks for periodicities of 9.6 years for Sicily and 12.0-9.6 years for Elbe basin. However, significant relations with the NAO or the ENSO were not found. In addition, other relevant peaks were close to the 11-year solar cycle. Telesca et al. (2013) used the SPI with various timescales and applied a spectral analysis to each local time series in the Ebro basin, Spain. For both the SPI-12 and 24, authors found cycles of 3.1, 4.1, 5.3, 8.8 and 17.6 years for most locations. The 3-5-year band was considered to be related to the NAO (Telesca et al., 2013). Various studies show that cyclicity can be found for precipitation, streamflow and droughts and that different methodological approaches lead to coherent results, with observed cycles relating well with those of the NAO, the AO and the ENSO, as well as with solar cycles. The detected cyclicity varies among sub-regions identified with PCA and cluster analysis. That cyclicity is both observed for Europe and elsewhere. The precipitation study by Liang et al. (2011) applied to Northwest China identified significant periods of 2.3 and 3.3 years, i.e. not very different from results by Bordi et al. (2004b) that characterized droughts with SPI-24 and studied their variability with PCA in eastern China. The application of a spectral analysis to a principal component led to the detection of peaks characterizing the interdecadal, decadal and interannual variability. A broad band peak was found for the interannual timescale of 3.74.0 years; other peaks lie near 6.9-8 up to 16 years and larger. Results by Liu et al. (2013) using the PDSI, also detected cycles of 3-5, 5-7 and 8-10 years throughout the Qinghai Province. Li et al. (2013) used clustering to define drought sub-regions in Southwest China with SPI and observed distinctive temporal evolution patterns of droughts in each subregion. The cycles varied from 2-3 years to 5-7 years.

The results of a previous study with log-linear models applied to droughts in southern Portugal showed the existence of a long-term periodicity that could reflect the natural variability of the climate (Moreira et al., 2006). This long-term periodicity was expressed by the alternation between long periods with high and low frequencies of severe and extreme droughts. A recent study using ANOVA-like inference coupled with log-linear models applied to 10 long series across Portugal also suggested a cyclic behaviour of droughts with periodicity ranging from 26 to 30 years, mostly for the sites in central and southern Portugal (Moreira et al., 2012). These studies suggested using Fourier analysis to detect the various cycles that contribute to the variability of droughts. Moreover, since cyclicity varies from one region to another (Bordi et al., 2004a, b, 2006; Raziei et al., 2009; Santos et al., 2010; Telesca et al., 2013), the use of PCA and cluster analysis has been considered for identifying possible regions within the country.

Recently, Martins at al. (2012) used PCA applied to the SPI-12 to identify the main spatial and temporal patterns of precipitation and drought in Portugal. This approach could then be combined with the Fourier analysis to verify if the cycles would change with the considered region.

Considering the review presented, the objective of this study is to detect the cyclicity of droughts defined through the SPI-12 and to observe when that cyclicity varies among identified regions within the country. On one hand, the analysis focused on the month of December, in the middle of the rainy season, and the cyclicity of negative peaks of the SPI12 , which indicate the possible cyclicity of droughts and any possible influence on drought occurrence of large-scale indices of atmospheric circulation. On the other hand, it was also aimed at analysing the cyclicity of the SPI-12 for the other months in the year, i.e. the dry and transition months. 
In contrast to Santos et al. (2010) and Telesca at al. (2013), the adopted approach applies Fourier analysis individually to each SPI-12 time series and an analysis of frequency on the significant cycles found inside each sub-region was performed in the following. Furthermore, a correspondence is sought between the minima of the sinusoidal functions and the moderate, severe and extreme drought events.

\section{Data, SPI, clustering and Fourier analysis}

\subsection{Base information}

The data consists of monthly precipitation time series from 1941 to 2006 (66 years) of 74 sites across Portugal (Fig. 1). Data from weather stations were obtained from the meteorological services (IPMA) and those of rainfall stations refer to the environmental services (SNHIR). Data quality was assessed using the Kendall autocorrelation test, the MannKendall trend test and the homogeneity tests of Mann Whitney for the mean and the variance (Helsel and Hirsch, 1992). To estimate missing values of monthly precipitation, maintenance of variance extension techniques were applied (Hirsch, 1982; Vogel and Stedinger, 1985). These data sets, previously used in other studies (e.g. Paulo et al., 2012; Martins et al., 2012; Raziei et al., 2014) were completed with techniques described by Rosa et al. (2010). Series retained did not have more than 250 gaps and all series covered the referred period of 66 years.

Precipitation based drought indices are the first indicators of droughts, since hydrological droughts may emerge several months after a meteorological drought has been initiated (Wilhite and Buchanan-Smith, 2005). The Standardized Precipitation Index, SPI (McKee et al., 1993, 1995), which is often used for identification of drought events and to evaluate their severity through well-defined drought classes, is adopted in this study following results obtained in previous studies characterizing droughts in Portugal (Paulo and Pereira, 2006; Santos et al., 2010; Martins et al., 2012).

The SPI is widely used because it is standardized and therefore allows a reliable comparison between different locations and climates (Mishra and Singh, 2010). It may be computed on shorter or longer timescales, which reflect different lags in the response of the water cycle to precipitation anomalies (Steinemann et al., 2005). In addition, due to its standardization, its range of variation is independent of the aggregation timescale of reference, as well as the particular location and climate. The 12-month timescale, as well as larger timescales, identifies anomalous dry and wet periods of relatively long duration and relates well with the impacts of drought on the hydrologic regimes and water resources of a region (Vicente-Serrano, 2006), or to the effects of fluctuation in rainfall over short intervals (Mishra and Singh, 2010).

Shorter timescales of less than 6 months are more useful for detecting agricultural droughts and while longer ones,

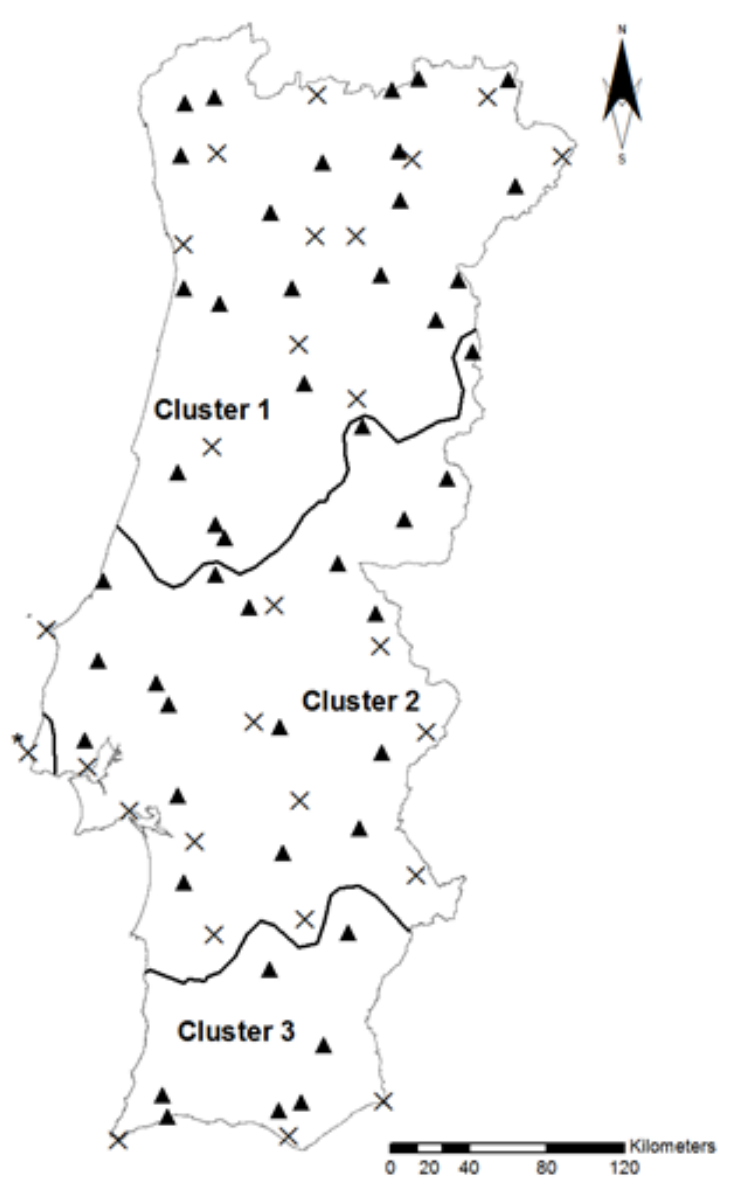

Figure 1. Spatial distribution of the meteorological stations $(x)$ and rainfall stations $(\boldsymbol{\Delta})$ used in the study and delimitation of drought clusters; (* station included in cluster 3$)$.

i.e. larger than 24 months, may be useful for considering impacts on groundwater resources. For the Portuguese conditions, where a dry summer period of nearly 6 months occurs, droughts impacting the hydrologic regime are better assessed using the 12-month timescale (Paulo and Pereira, 2006; Santos et al., 2010). Hence, previous studies on drought variability and drought class transitions were performed with the SPI 12-month (Moreira et al., 2006, 2012; Martins et al., 2012). Therefore, time series of SPI with a 12-month timescale (SPI-12) were computed from the 74 monthly precipitation time series. The respective monthly drought classes were then computed based on Table 1.

The computation of the SPI index (Guttman, 1999) in a given year $i$ and calendar month $j$, for a $k$ timescale was performed with the following steps: (i) calculation of a cumulative precipitation series

$X_{(i, j)}^{k}, i=1, \ldots, n ; j=1, \ldots, 12, k=1,2, \ldots, 12, \ldots$

for that calendar month $j$, where each term is the sum of the actual monthly precipitation with the precipitation of the $k-1$ past consecutive months; (ii) fitting of a gamma distri- 
Table 1. SPI drought class classification (McKee et al., 1993).

\begin{tabular}{lllr}
\hline Code & $\begin{array}{l}\text { Drought } \\
\text { classes }\end{array}$ & SPI values & $\begin{array}{r}\text { Time in } \\
\text { category }(\%)\end{array}$ \\
\hline 1 & Non-drought & SPI $\geq 0$ & \\
2 & Near normal & $-1<\mathrm{SPI}<0$ & 34.1 \\
3 & Moderate & $-1.5<\mathrm{SPI} \leq-1$ & 9.2 \\
4 & Severe & $-2<\mathrm{SPI} \leq-1.5$ & 4.4 \\
5 & Extreme & SPI $\leq-2$ & 2.3 \\
\hline
\end{tabular}

bution function $F(x)$ to the monthly series; (iii) computing the non-exceedance probabilities corresponding to the cumulative precipitation values; (iv) transforming those probabilities into the values of a standard normal variable, which are actually the SPI values. For example, when $k=12$ months, the SPI in December includes the effect of precipitation in December and in the previous 11 months. For the climate of Portugal, SPI-12 values of December are considered a good reference for drought monitoring because this month is central in the rainy season; thus, when droughts occur the effect of lack of precipitation in the previous months is then well detected. In contrast, selecting a summer month, for instance July, which falls in the dry season where precipitation is almost non-existent, the dryness identified may not be significant for drought monitoring despite the fact that the SPI-12 in July considers the effect of all precedent 11 months. In this study, the main focus of the Fourier analysis was on the SPI12 for December, where the significant cycles retained for continental Portugal are discussed (Sect. 3.2). Additionally, a discussion of the drought cycles found using the SPI-12 for the remaining months, January-November, is provided in Sect. 3.3.

In order to identify regions with the same spatial and temporal patterns of droughts, a PCA on the SPI-12 was performed and followed by a K-means clustering of the PC loadings provided by the PCA. The adoption of PCA followed by a cluster analysis is justified by the need to take into consideration the spatial variability of the periodicity that droughts may assume. The PCA is a method commonly used in studies of climate and is often applied to drought indices and precipitation to identify their patterns (Bordi et al., 2004a, b, 2006; Raziei et al., 2009; Santos et al., 2010). This method allows reduction of the original dimensionality of the data through forming new uncorrelated variables that are linear combinations of the original ones and explain a large portion of the total variance (Sharma, 1996). Here, the PCA was applied in the S-mode (Richman, 1986), using the 74 SPI-12 time series in order to capture the drought variability which shows the co-variability between stations considering its time variability (Martins et al., 2012). Furthermore, to identify regions with different drought variability, the varimax rotation was used (Raziei et al., 2009).
The loadings obtained from the PCA, which represent the correlation between the original data and the principal components series, were then submitted to a cluster analysis. This classification method is used to detect variables that are more similar to each other and categorize them together in different clusters (Sharma, 1996). From the various types of methods, the K-means clustering was used herein since it is suitable for climate data and also facilitates comparison of the results with previous studies that used the same method (Santos et al., 2010).

\subsection{Fourier analysis of SPI-12 time series}

Regular or near-regular cycles are often encountered in nature. The Fourier analysis methodology can be referred to as a method for uncovering hidden periodicities and, in particular, extracting regular cyclical components from the time series when the quantity of data is not excessively large. Fourier analysis is a method based upon the Fourier decomposition of a series, which is a matter of explaining the series entirely as a composition of sinusoidal functions. This originates in the idea that, over a finite interval, any analytic function can be approximated, to whatever degree of accuracy is desired, by taking a weighted sum of sine and cosine functions (Pollock, 1999).

Let $m=n / 2$ if $n$ is even or $m=(n-1) / 2$ if $n$ is odd, with $n$ the number of observations in a time series. The general model for a cyclic fluctuation would include the frequencies, $\omega_{j}=(2 \pi j) / n, j=0, \ldots, m$ which are equally spaced in the interval $[0, \pi]$ and take the form

$y_{t}=\sum_{j=0}^{m}\left\{\alpha_{j, 1} \sin \left(\omega_{j} t\right)+\alpha_{j, 2} \cos \left(\omega_{j} t\right)\right\}+e_{t}$,

where $t$ represents time, $\alpha_{j, 1}$ and $\alpha_{j, 2}, j=0, \ldots, m$ are estimable parameters and $e_{t}, t=1, \ldots, n$ are independent and identically distributed random variables with null mean value and variance $\sigma^{2}$, representing the residual element which is called the white noise process (Pollock, 1999).

The factor $\theta_{j}=\sqrt{\alpha_{j, 1}^{2}+\alpha_{j, 2}^{2}}, j=0, \ldots, m$, is the amplitude of the $j$ th periodic component and indicates the importance of that component within the sum. The parameters $\alpha_{j, 1}$ and $\alpha_{j, 2}, j=0, \ldots, m$ are estimated using the least squares method and the expressions for their estimators are given by (Pollock, 1999)

$$
\begin{aligned}
& \widetilde{\alpha}_{0,2}=\frac{\sum_{t=1}^{n} y_{t}}{n} ; \widetilde{\alpha}_{j, 1}=\frac{2 \sum_{t=1}^{n} \sin \left(\omega_{j} t\right) y_{t}}{n} ; \\
& \widetilde{\alpha}_{j, 2}=\frac{2 \sum_{t=1}^{n} \cos \left(\omega_{j} t\right) y_{t}}{n}, j=1, \ldots, m .
\end{aligned}
$$

Then an estimator for $\theta_{j}, \widetilde{\theta}_{j}$, can be obtained and a statistic to test the significance of the $j$ th periodic component is given by (Fisher, 1929; Nowroozi, 1967)

$$
g_{j}=\frac{\widetilde{\theta}_{j}^{2}}{\sum_{i=1}^{m} \widetilde{\theta}_{i}^{2}}, j=1, \ldots, m .
$$


The total sample variance is given by $\sum_{j=1}^{m} \frac{\widetilde{\theta}_{j}^{2}}{2}$ and the proportion of that variance which is attributable to the periodical component at frequency $\omega_{j}$ is $\frac{\widetilde{\theta}_{j}^{2}}{2}$.

In order to provide a graphical representation of the sample variance decomposition, the elements of the total variance must be scaled by a factor of $n$. The graph of the function $I_{j}=\frac{n \widetilde{\theta}_{j}^{2}}{2}$ is known as the classical periodogram (Pollock, 1999). The graphic representation of $I_{j}$ for $j=1, \ldots, m$ (Fig. 2), allows one to detect the existence of relevant periodic components of the time series, as well as the importance of each one. The wavelength, i.e. the period in time units of the $j$-th periodic component, is given by $p_{j}=n / j$.

In the current study, the number of observations is $n=66$ in all locations, thus $m=33$. For each of the studied time series, the $I_{j}$ for $j=1, \ldots, m$ was calculated and graphically represented in order to visualize the highest peaks, which correspond to the leading periodic components of the time series. The observation of several high peaks indicates the existence of several periodic components with different periods. However, in general, few of those peaks represent a strong periodical signal that cannot be assigned to statistical fluctuations in a merely white noise process.

The assessment of the statistical significance of a peak involves testing the null hypothesis, $H_{0}$, that the observed time series are purely white noise against the alternative, $H_{1}$, stating that a periodic signal is present there. The statistical distribution of the periodogram is well known for the evensampling case, which corresponds to equally spaced observations (Scargle, 1982). The most important result is that if the observations in the time series are pure Gaussian noise the $I_{j}, j=1, \ldots, m$ are independent and exponentially distributed. In this situation, it is reliable to use the false alarm probability to assess the statistical significance of the highest peaks in the periodogram, which states that if $Z=\max \left(I_{j}\right)$, $j=1, \ldots, m$ is a maximum value of the periodogram, then the probability for $Z$ being over the set of the $m$ periodogram values is given by

$\operatorname{Pr}(Z>z)=1-[1-\exp (-z)]^{m}$.

So, a threshold $z_{0}$ can be used for detecting if a peak is significant, which is defined as

$z_{0}=-\ln \left[1-\left(1-p_{0}\right)^{(1 / m)}\right]$

where $p_{0}$ is the false alarm probability, a fixed small value usually selected between 0.01 and 0.1 (Scargle, 1982). For instance, in the "Reguengos" December SPI-12 time series (Fig. 2) the highest peak is attained for $j=11\left(I_{11}=9.05\right)$, which corresponds to a periodic component with a 6-year period. Choosing a false alarm probability of 0.1 , with the number of periodical components $m=33$, the value $z_{0}$ obtained is 5.75 , which allows one to conclude that the peak is significant. In this time series, two other peaks are significant, those for $j=2$ and $j=7$ corresponding to sinusoidal
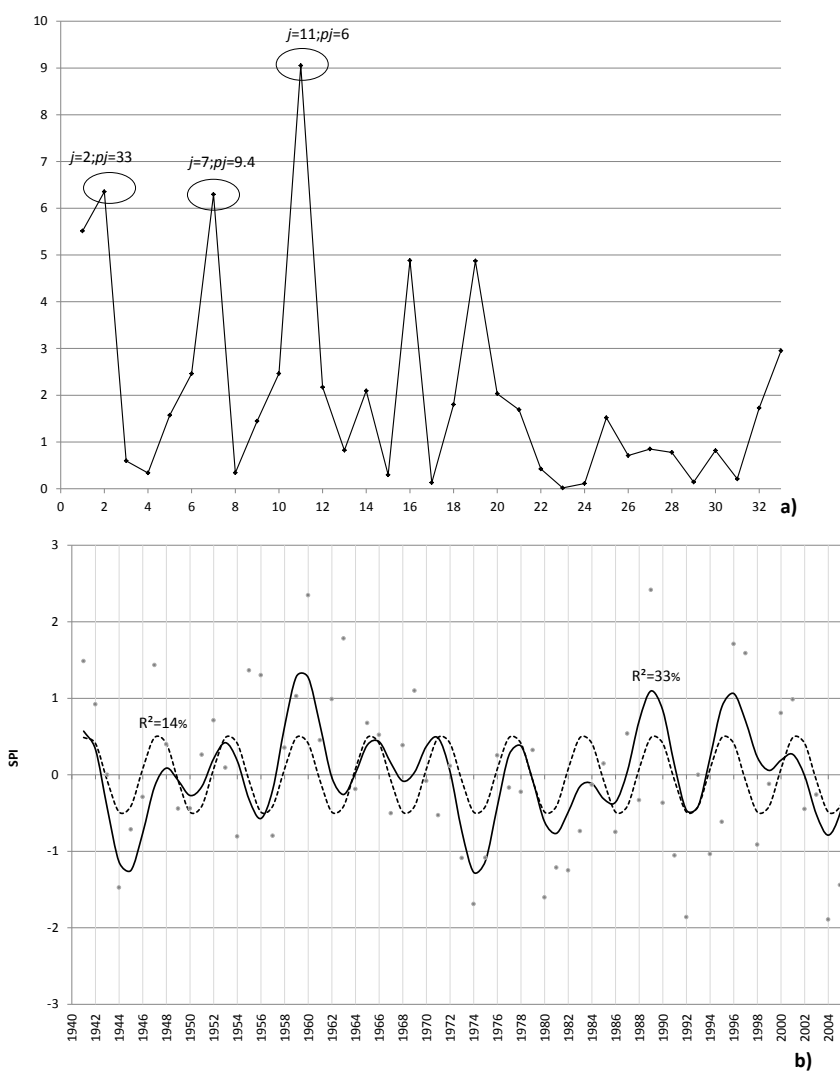

Figure 2. Reguengos: (a) graph of $I_{j}, j=1, \ldots, 33$; (b) SPI December values (grey dots) vs. fitted sinusoidal wave of 6 -year period (dashed line) vs. fitted model resulting from summing up the waves with period 6, 9.4 and 33 years (black line).

waves with 33- and 9.4-year periods (Fig. 2). If one considers a false alarm probability of 0.01 instead of 0.1 , then only the peak for $j=11$ with a 6 -year period can be considered significant.

The fitted sinusoidal function of 6-year period is presented in Fig. 2 simultaneously with the Reguengos time series and obviously has the best goodness of fit to the time series among all other periodic components, $R^{2}=0.14$ (dashed line). For a better goodness of fit between the sinusoidal wave and the time series, the cycles corresponding to the significant peaks in the periodogram can be summed up, thus $j=2+7+11$, to build a general model for a nonregular cyclic fluctuation. In Fig. 2, the wave resulting from summing up the significant cycles with periods $6,9.4$ and 33 years (black line) is also represented. Some improvement of the goodness of fit is then obtained, with $R^{2}=0.33$. 


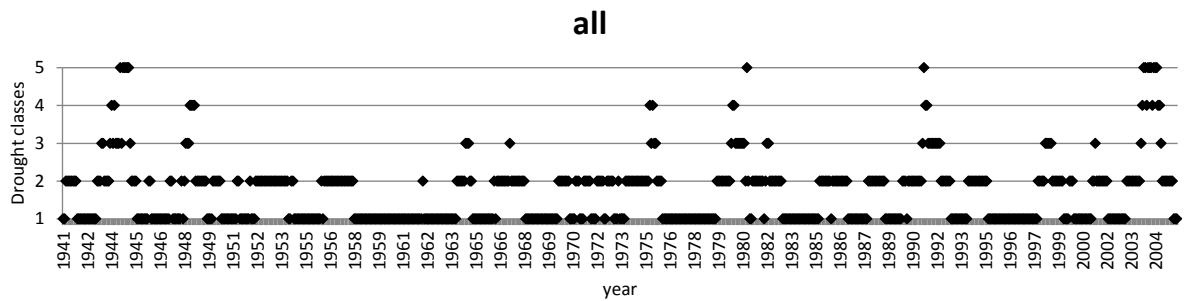

cluster 1

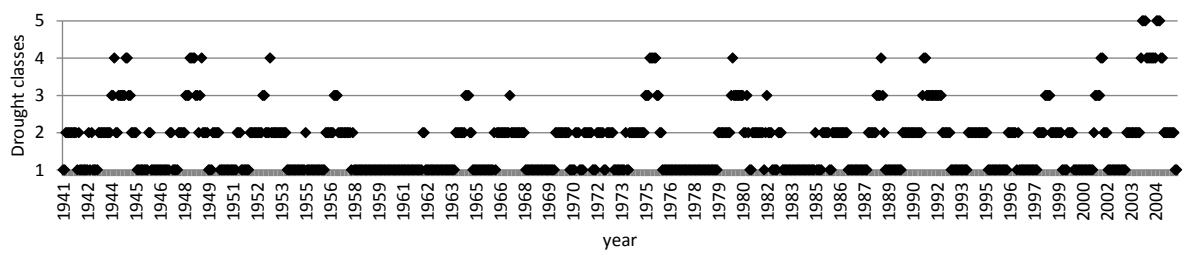

cluster 2

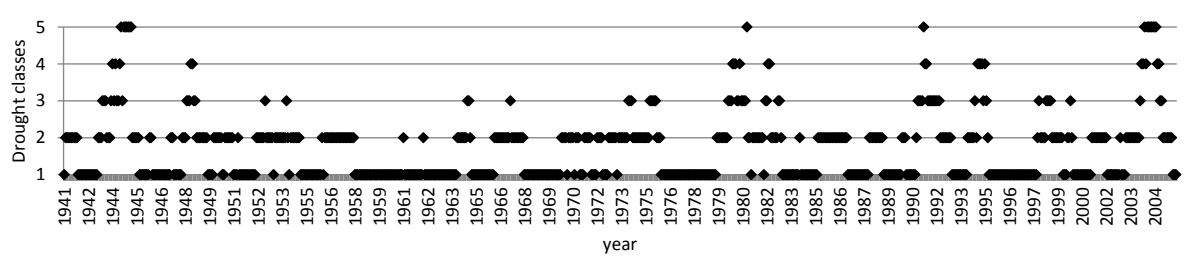

cluster 3

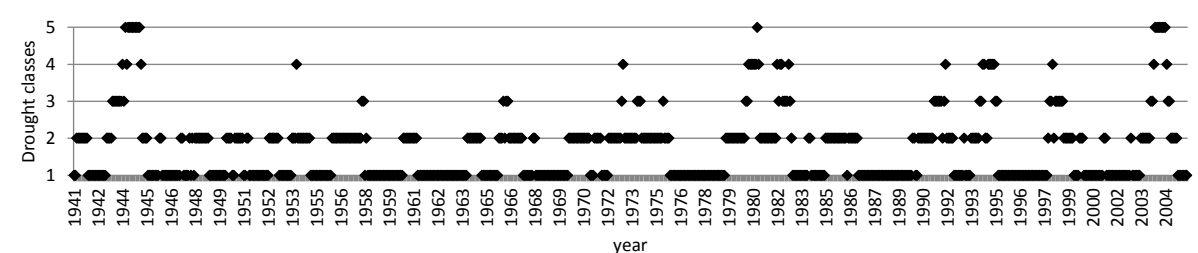

Figure 3. The most frequent drought class by month in Portugal (all), cluster 1, cluster 2 and cluster 3 ( 1 - non drought, 2 - near normal, 3 - moderate, 4 - severe, 5 - extreme).

\section{Results and discussion}

\subsection{SPI spatial and temporal variability - drought clustering}

Based on North's rule of thumb (North et al., 1982), two principal components were retained from the PCA, which were submitted to the varimax rotation. The first component, with the highest loading in the north, explains $46 \%$ of the total variance and the second one, related to the south, explains $37.3 \%$. Both components explain $83.3 \%$ of the total variance (Martins et al., 2012).

The K-means clustering of the loadings of these two principal components shows three significantly different regions within Portugal relative to drought variability, thus separating the north from the centre and the south sub-regions (Fig. 1). The identified clusters are consistent with the results found by Santos et al. (2010), although using different time-series with different lengths. The specific characteristics of the sta- tion of Cabo da Roca (represented with * in Fig. 1) makes it closer to the drought variability of cluster three relative to the second cluster; for that reason the analysis was performed including that station in the southern cluster.

The most frequent drought class, i.e. the statistical mode in each month for each of the three clusters were computed to provide a global overview on the temporal evolution of the drought classes in each of the corresponding regions (Fig. 3). In this study, a drought event is considered a sequence of months with drought class 3 or higher where the interval between droughts does not exceed 2 years. Thus, considering this assumption, when observing Fig. 3 it can be noted that during the entire 66-year time period there are 13 groups of drought events in cluster 1 ; if considering just the classes 4 and 5 , this number decreases to 9 . For cluster 2 , the number of drought events of classes 3-5 is 11 and decreases to 6 when considering only the classes 4 and 5 . For cluster 3 , the number of events of class 3 or higher is 10 and, if considering 
Table 2. The counts per cycle and per cluster and its frequency (\%) relative to the number of series included in each cluster (just the significant cycles of the periodograms).

\begin{tabular}{lrrrrrrrrrrrr}
\hline Counts & Nr. series & 33.0 & 22.0 & 16.5 & 9.4 & 6.6 & 6.0 & 4.7 & 4.4 & 3.3 & 2.6 & 2.0 \\
\hline & & & & \multicolumn{7}{c}{ Period in years } \\
\hline Cluster 1 & 32 & 3 & 2 & 1 & 2 & 0 & 27 & 13 & 3 & 0 & 1 \\
Cluster 2 & 30 & 5 & 0 & 0 & 15 & 0 & 27 & 0 & 0 & 0 & 0 & 5 \\
Cluster 3 & 12 & 2 & 0 & 0 & 12 & 3 & 11 & 0 & 0 & 2 & 0 & 3 \\
Total & 74 & 10 & 2 & 1 & 29 & 3 & 65 & 13 & 3 & 2 & 1 \\
\hline Frequency & & 33.0 & 22.0 & 16.5 & 9.4 & 6.6 & 6.0 & 4.7 & 4.4 & 3.3 & 2.6 & 2.0 \\
\hline Cluster 1 & & $9.4 \%$ & $6.3 \%$ & $3.1 \%$ & $6.3 \%$ & $0.0 \%$ & $84.4 \%$ & $40.6 \%$ & $9.4 \%$ & $0.0 \%$ & $3.1 \%$ & $0.0 \%$ \\
Cluster 2 & $16.7 \%$ & $0.0 \%$ & $0.0 \%$ & $50.0 \%$ & $0.0 \%$ & $90.0 \%$ & $0.0 \%$ & $0.0 \%$ & $0.0 \%$ & $0.0 \%$ & $16.7 \%$ \\
Cluster 3 & $16.7 \%$ & $0.0 \%$ & $0.0 \%$ & $100.0 \%$ & $25.0 \%$ & $91.7 \%$ & $0.0 \%$ & $0.0 \%$ & $16.7 \%$ & $0.0 \%$ & $25.0 \%$ \\
\hline
\end{tabular}

only the classes 4 and 5 , that number decreases to 8 . These results do not show a clear tendency, as one moves from north to south, regarding the severity and frequency of droughts; however, considering only the extreme droughts it can be observed that there are more events in the central and southern clusters, four and three against just one in the northern region. From the observation of the three clusters in Fig. 3, one may observe that the minimum time interval between groups of severe and extreme drought occurrences is about 4 years and the maximum time without severe droughts is approximately 27 years. This large period of 27 years without severe and extreme droughts, which is observed in the first half of the studied period, could indicate a trend towards drought aggravation. However, as reported by Moreira et al. (2012) using 10 time series with around 100 years length, there was no evidence of a trend for aggravation. In contrast, for most sites, results pointed to the occurrence of large cycles such that a long period with more frequent and severe droughts is followed by another long period where droughts are less frequent and less severe (Moreira et al., 2012).

\subsection{Fourier analysis - application to SPI-12 relative to December}

The periodograms of the 12 SPI-12 subsets relative to January-December values were computed for all the 74 locations and the significance of the cycles was analysed using the false alarm probability considering the 0.1 significance level, i.e. only the peaks above $90 \%$ confidence level were considered significant. The results referring to the periods of the cycles corresponding to the significant peaks recorded in the periodograms for the subset time series consisting of the December values are compiled in Table 2 and grouped by clusters. The counts per period and per cluster are presented in this Table as well as the corresponding frequency relative to the number of series included in each of the three clusters expressed as percentage.

Considering the country total, the most frequent cycles are those with periods of 6 years (65) and 9.4 years (29) (Ta- ble 2 counts total). When analysing the counts by cluster, because clusters have different numbers of series, the frequency in percent for each cluster is used (Table 2). In cluster 1 , the most frequent cycles ordered by frequency are 6-year $(84.4 \%)$ and 4.7-year $(40.6 \%)$. In cluster 2, they are 6-year $(90 \%)$ and 9.4-year $(50 \%)$, while in cluster 3 there are 9.4year $(100 \%)$ and 6-year $(91.7 \%)$. The interdecadal cycles with periods of 33 years are present in all regions but cycles with $22,16.5$ and 13.2 years are only present in the northern region (cluster 1 ).

Just three of the significant cycles found in the SPI-12 time series have frequencies sufficiently high in the entire country or in each of the three clusters: first, the cycle with a period of 6 years, which has very high frequency (84-92\%) in the three clusters; second, the cycle with a period of 9.4 years with very high frequency $(100 \%)$ in cluster 3 and median frequency $(50 \%)$ in the cluster 2 ; third, the cycle with a period of 4.7 years which is moderately frequent $(41 \%)$ in cluster 1 . These results show that the cyclicity of droughts varies among regions. In summary, the cycle with a 6-year period has a very strong presence in the whole country whereas the cycle with a 9.4-year period has a stronger presence in the southern rather than in the central/northern region of Portugal. The cycle of 4.7-year period is non-existent in central and southern regions and it only appears in the northern cluster.

Against our expectations, the large cycles with more than a 20-year period have low frequency in all clusters. This fact may relate to the technique adopted associated with the relatively short length of time series, much shorter than those used by Moreira et al. (2012). For instance, the large cycles of 33 years are mainly frequent in cluster 2 and 3 , but most of them were not found significant in the periodogram.

Looking at the results from a point of view of inference, since the number of time series included in cluster 1 and 2 is large, respectively 32 and 30 stations, each one can be considered as a random sample respective of northern and central regions. Thus, taking the counts of Table 2, an estimate for 
the probability that the return period of droughts is 6 years in cluster 1 is given by $27 / 32=84.4 \%$. In cluster 2 that estimate is $27 / 30=90 \%$. Relative to cluster 3 , the probability estimates of 91.7 and $100 \%$ respectively of the return period of droughts being 6 and 9.4 years is likely overestimated because the number of time series in the sample is only 12 and their spatial distribution is not the best; thus the sample may not be representative of the population, even taking into account that cluster 3 is small. However, for the entire country a reliable estimate for the probability of a 6-year return period is given by $65 / 74=87.8 \%$.

In Figs. 4, 5 and 6, the time series for the SPI-12 relative to December for the three clusters are shown with superposing the most frequent waves: one of 4.7-year period in cluster 1, another of 6-year period in clusters 1, 2 and 3, and a wave of 9.4-year period in clusters 2 and 3. A correspondence between the minima of the waves and the SPI upper borders for moderate drought $(-1)$ and for severe and extreme drought $(-1.5)$ is established through arrows placed in these figures. In Fig. 4, relative to cluster 1, one can observe that the wave of 6-year period has 11 minima and nearly all of them coincide with events of moderate $(-1.5<\mathrm{SPI}<-1)$ or severe and extreme droughts (SPI $<-1.5$ ). Just one drought event, in 1957, was missed by the wave. Therefore, a good visual agreement exists between the minima of the sinusoidal wave of 6-year period and the events of moderate or more severe droughts that occurred during the study period. Relative to the wave of 4.7-year period in cluster 1 , from a total of 14 minima about 11 coincide with events of moderate, severe and extreme drought. The degree of agreement for this wave is less good than for the one with a 6-year period.

For cluster 2 (Fig. 5) a good agreement between the minima of the 6-year period wave and the events of moderate, severe and extreme droughts was observed; as for cluster 1, the same drought event of 1957 was missed by the wave. As for the wave of 9.4-year period, six out of a total of seven minima coincide with events of moderate, severe and extreme droughts. For cluster 3 (Fig. 6), the visual agreement between the wave of 6-year period and the drought events is not as good as for the previous clusters, with three of the minima not coinciding with drought events and with two events of moderate drought and one of severe drought missed by the wave. Relative to the 9.4-year wave, one out of the seven minima does not correspond with a drought event. Furthermore, two moderate and one severe and extreme drought events are missed by the wave. However, this less good agreement for cluster 3 may be due to the low number of time series included there. In general, a visual relation can be established between the Fourier waves and the events of drought that occurred in each cluster during the study period. The correspondence between the sinusoidal waves and the drought cyclicity is not perfect because cycles in nature are only near-regular, thus not providing for a full agreement with regular waves.

\subsection{Application of Fourier analysis to SPI-12 time series relative to the rainy, transition and dry months}

The results of the Fourier analysis applied to the SPI relative to the months of January-November are summarized in Table A.1 in the Appendix and illustrated in Fig. 7. The analysis is performed considering three distinct groups: (1) a rainy season including November, December and January; (2) a dry season including the months between May and September; and (3) the transition months of February, March, April and October. The most frequent significant cycles found for December values, namely the 6, 9.4 and 4.7-year, are also observed in the remaining months. The 6-year cycle is present in the applications to all months but is less frequent in the dry season. The 9.4-year cycle is less frequent, and can only be found in cluster 3 for the rainy season. Other short-period cycles with 3.1, 2.6 and 2-year show up with high frequency for the dry season and the transition months.

Taking a closer look to Fig. 7, the following cycles are in evidence:

- the 2-year cycle is frequent in the south, cluster 3 , in the dry season;

- the 2.6-year cycle is found in the dry season and in the transition months in cluster 1 and in the transition months in cluster 2 ;

- the 3.1-year cycle has high frequency in clusters 2 and 3 in the transition months and the dry season;

- the 4.7-year cycle is present in the three clusters for October and November. Cluster 1 also shows the 4.7 year cycle in December and January;

- the 6-year cycle has high frequency in general in all clusters and months but not in the dry season months in cluster 1 ;

- the 9.4-year cycle has high frequency in cluster 3 for the months of the rainy season and, for the cluster 2 , just for December.

\subsection{Discussion}

The time series relative to every month, January through December, show a behaviour that differs for each month, which relates to the conditions regulating the general circulation of the atmosphere that also vary throughout the year. The short period cycles of 2-3.1 years are in general statistically significant in the months from March to September, thus out of the rainy months. For the locations where the short cycles are significant, waves of 2.6 or 3.1-year period were compared with the correspondent SPI time series (not shown). The maximum values of the wave have been shown to better agree with the SPI $>1.0$, i.e. when the precipitation is above 


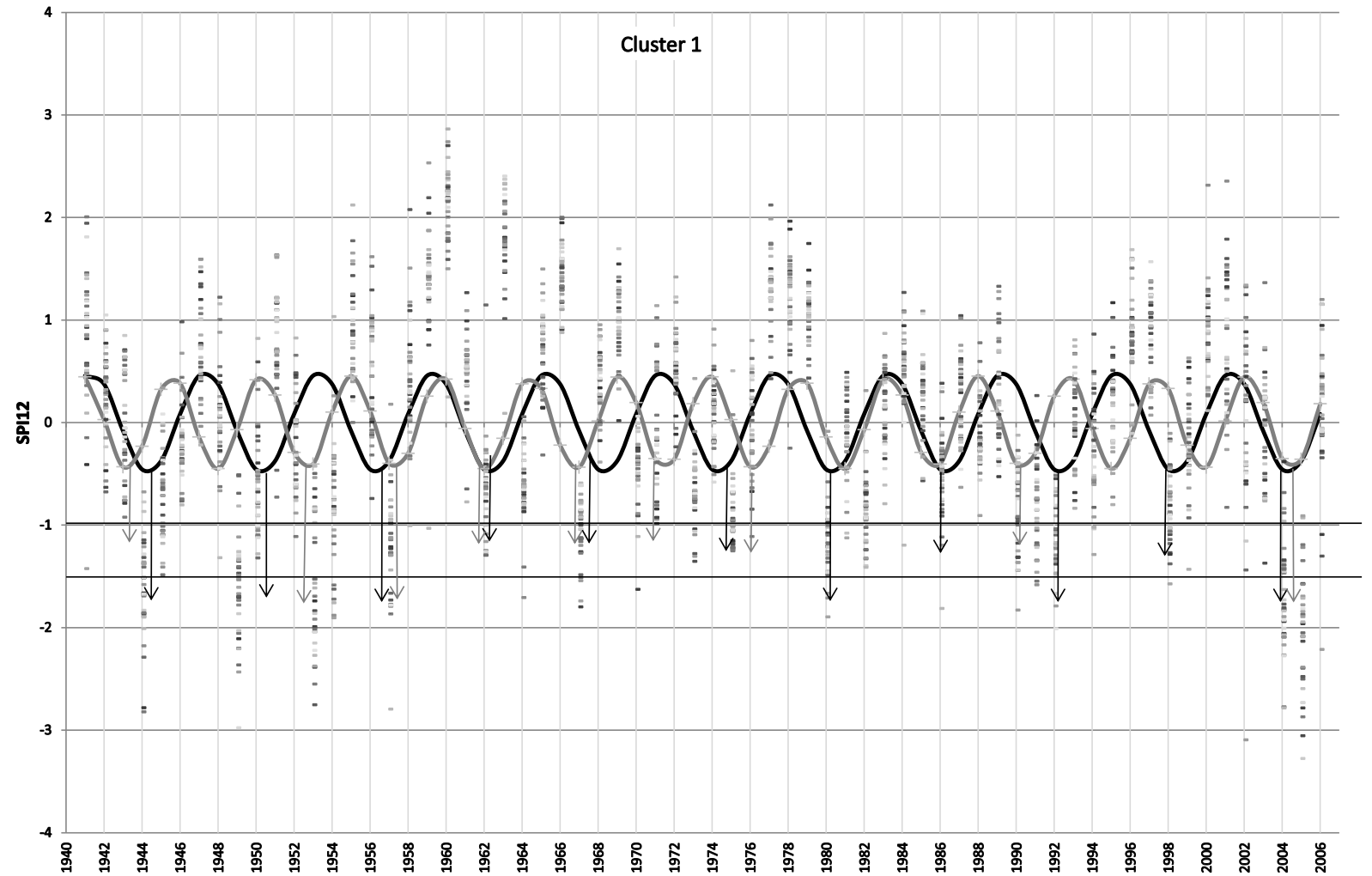

Figure 4. SPI-12 December values for northern Portugal (cluster 1) + waves of period 4.7 years (grey line) and 6 years (black line).

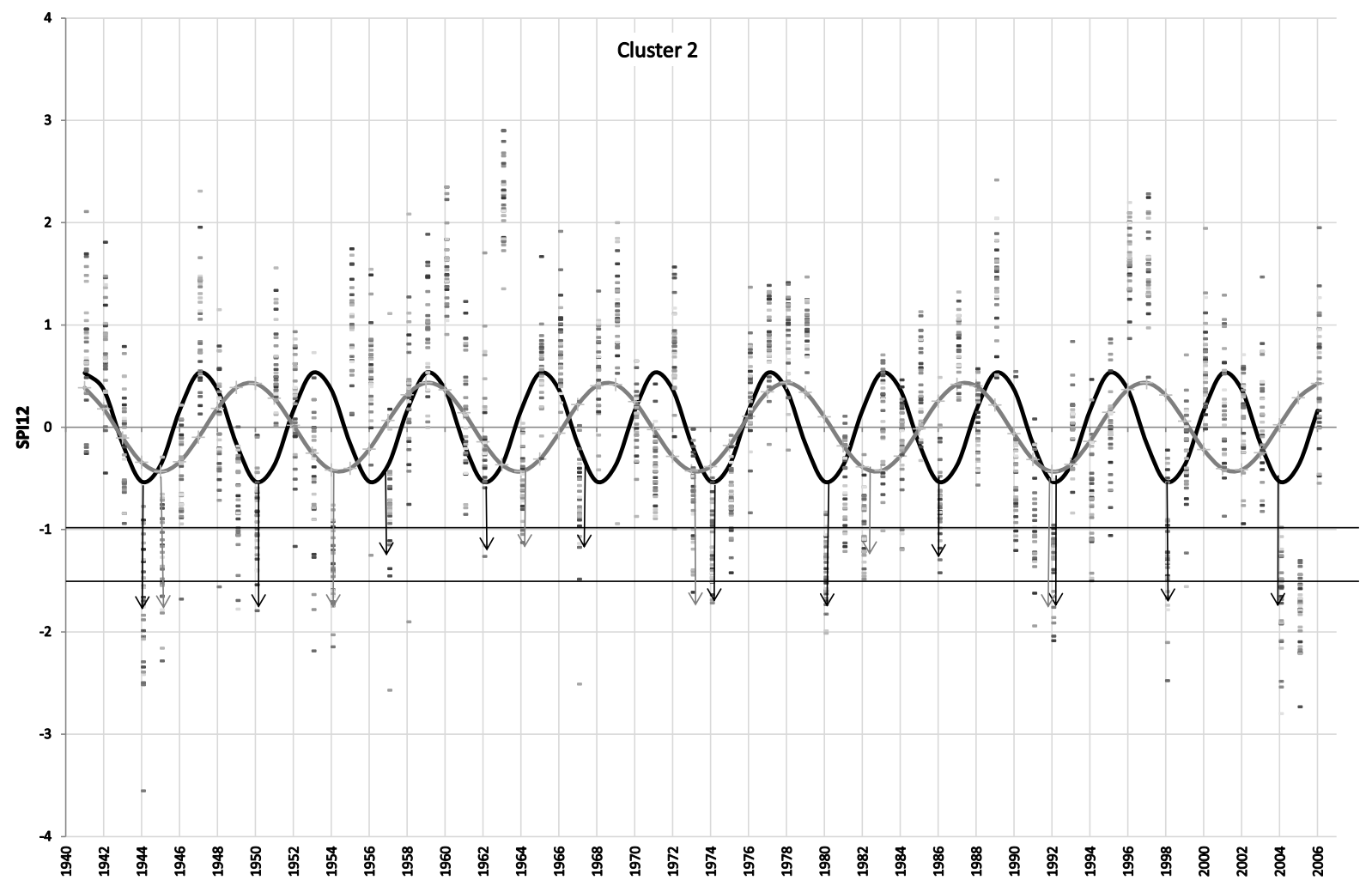

Figure 5. SPI-12 December values for central/southern Portugal (cluster 2) + waves of period 6 (black line) and 9.4 years (grey line). 


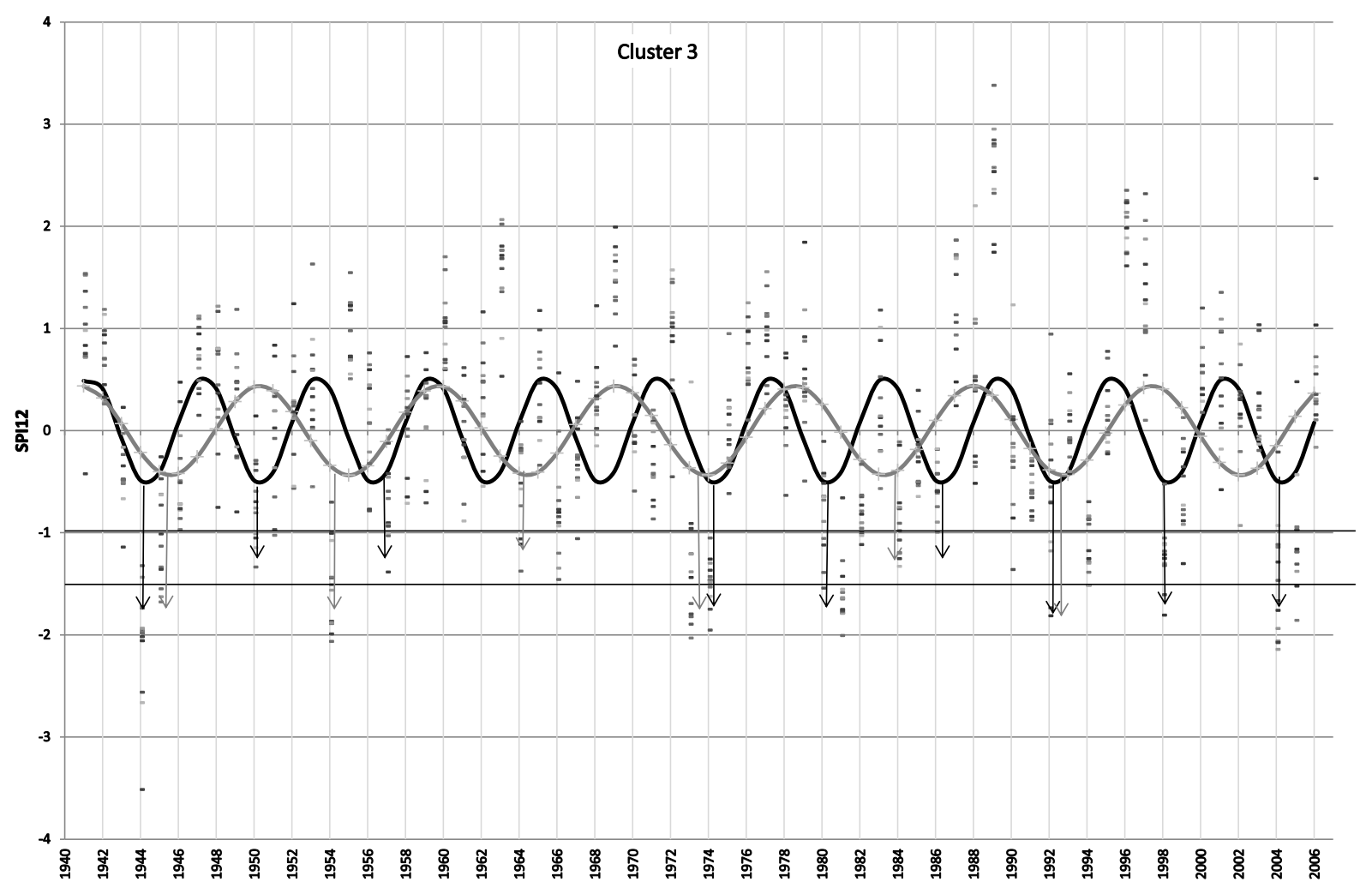

Figure 6. SPI-12 December values for southern Portugal (cluster 3) + waves of period 6 (black line) and 9.4 years (grey line).

normal. This may indicate that the short cycles relate with wet rather than dry years, therefore they are not useful to assess drought behaviour.

Medium-period cycles are mainly statistically significant in the months from November to April. The cycles of 6 and 9.4 years are representative of drought cyclicity since, as seen previously (Sect. 3.2), there is a good agreement between the Fourier waves and the drought events that occurred in all clusters. Furthermore, in the years where a drought is installed, the December values of the SPI-12 reflect this situation through assuming highly negative values. This fact denotes the effect of the lack of precipitation in the precedent rainy months; the same occurs with the SPI-12 relative to January and February. Contrarily, in the rainy years, the SPI12 from May to September reflect precipitation above normal that occurred in the precedent rainy and transition months. Therefore, the short cycles, which relate with precipitation above normal, are significant in the SPI values from May to September, while the medium cycles, which relate with drought, are significant for the months November to April.

The NAO plays a fundamental role in the Atlantic and European climate, in particular, the negative phase of the NAO regime is fundamental for the winter interannual variability of precipitation in Portugal (Santos et al., 2005), whereas positive phases of the NAO are usually associated with drought conditions (Santos et al., 2005, 2007). Vari- ous studies have shown that the NAO influences precipitation (Trigo et al., 2002; Pires and Perdigão, 2007) and streamflow (Trigo et al., 2004; Bierkend and Van Beek, 2009). Thus, it is reasonable to relate the cyclicity of drought events with large circulation patterns such as the NAO. Santos et al. (2007) studied the physical mechanisms responsible for the extremely dry winter of 2004/2005 in Portugal and concluded that the strengthening of the NAO toward its positivephase contributed to the extreme conditions of that particular winter. Also, Sousa et al. (2011) showed significant correlations between dry periods, measured with the self-calibrated PDSI, and the positive phase of the NAO during winter on the region.

Given the NAO influences reported in the precedent paragraph, and the fact that a period of fluctuations of the NAO index of 6-10 years has been found for Eurasia (Pollonskii et al., 2004), the 6 and 9.4-year cycles identified in this study, mainly relative to the winter months, are likely related to positive values of the NAO in the winter. However, the identified NAO influence is only a first and rough approximation since other large-scale patterns are also significantly coupled with the winter precipitation in Portugal, e.g. the AO influences (Santos et al., 2009).

Labat (2006) also assumed NAO influences on European surface water regimes in terms of multidecadal periods. However, in agreement with conclusions by Santos et 

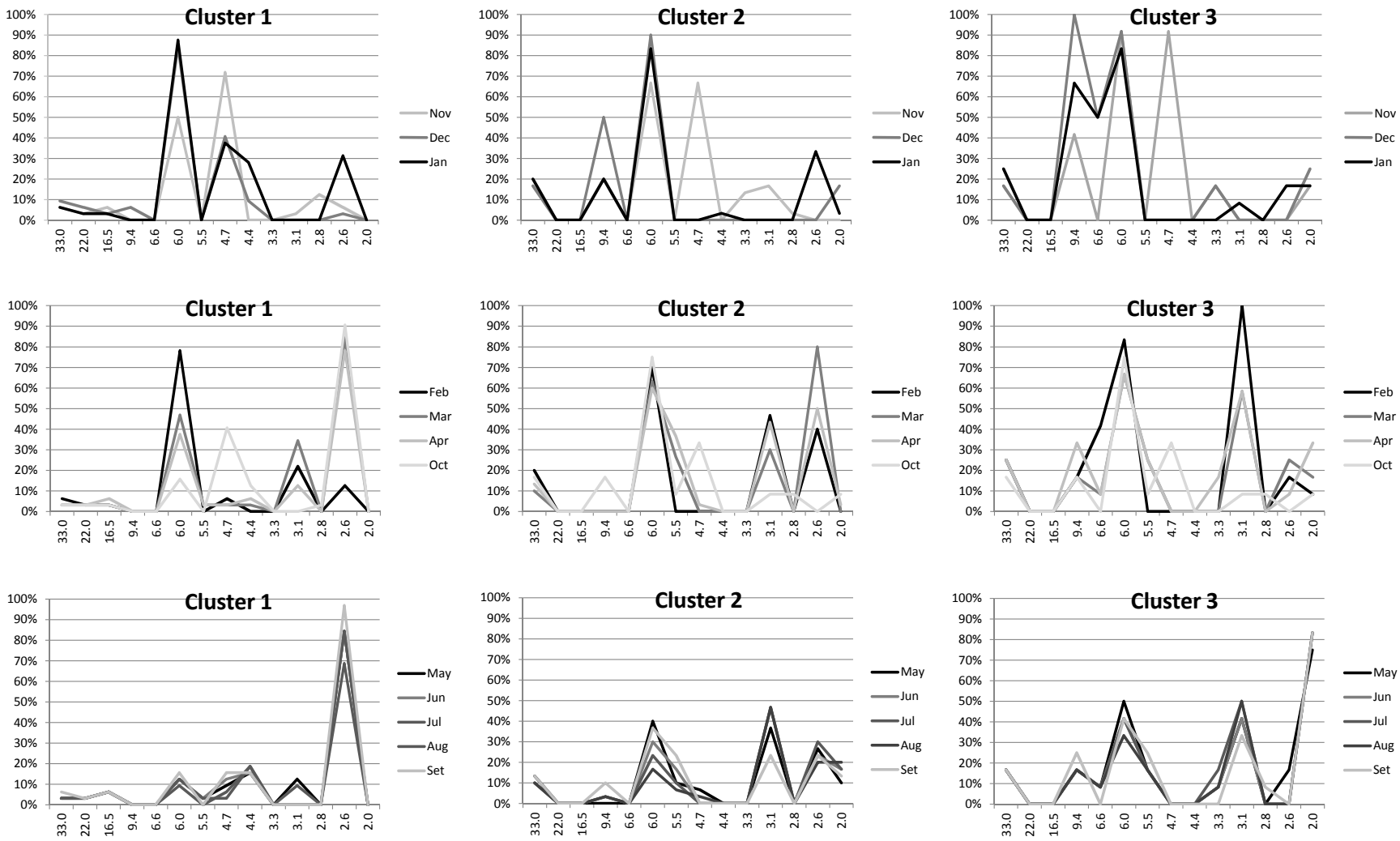

Figure 7. Frequencies relative to each cluster per period cycle, gathered in three groups: November, December and January (wet season); February, March and April (transition months); and May-September (dry season).

al. (2010), periodicities of more than 10 years, more frequent in the northern region, are difficult to relate with the NAO. This was also concluded by Kücük et al. (2009) for Turkey. Following the results reported by Tsiropoula (2003) and Hathaway (2010), these multidecadal cycles may relate to solar cycles.

\section{Conclusions}

Three main sub-regions characterized by different drought variability were identified by combining principal component analysis applied to SPI-12 time series with cluster analysis. A Fourier analysis was then applied to all SPI-12 timeseries included in the three sub-regions or clusters defined. This approach differs from those that normally apply the spectral analysis on the principal components of the studied variables. Herein the Fourier analysis is applied individually to each SPI time series and the frequency of the significant cycles is analysed for each cluster.

The Fourier analysis, used to search for significant cycles that could relate to return periods of droughts, was performed using a SPI-12 time series respective to each month. The results of this analysis for the SPI-12 relative to December values are of particular interest since they are a good indica- tor for drought monitoring for the Portuguese climatic conditions.

Results show that drought periodicities vary among the three sub-regions and differ when different months are considered for the Fourier analysis. For the SPI-12 relative to December, the main cycles identified are: (i) a cycle with a 6-year period compatible with NAO influences, doubtless the most frequent across the country and, that generally shows a good agreement with the range time of the drought events that occurred in each region; (ii) the cycle of 9.4 years, also likely related to the NAO, but that loses importance from south to north, where it is nearly non-existent; (iii) the cycle with a small period of 4.7 years, that is fairly frequent in the northern region but is not significant in the central and southern regions.

These results point to northern and southern Portugal having different climatic influences that cause the strong presence of cycles with periodicities in the range of 6-10 years in the time series of central/southern regions. As for the cycles of SPI-12 in the remaining months, the results show that the 4.7, 6, 9.4-year cycles can also be found but their frequency varies with latitude (cluster) and with the month that is considered. From October to January, the 4.7-year cycle is evident in all clusters; the 6-year cycle is also frequent, but it cannot be found in the dry season in the north, cluster 1; 
the 9.4-year cycle is also quite frequent, but only in the rainy months.

Shorter cycles, $2-3$ years, are identified and are significant in the dry months in the south and in the transition months in the north and centre. However they seem to be associated with cycles related to wetness, i.e. SPI $>1.0$, instead of drought. The adopted methodology, simpler than other more complex techniques such as the wavelet transform analysis, allowed a good understanding and interpretation of the drought periodicity. Furthermore, the Fourier analysis may also be useful in long term drought prediction as it may provide an estimative relative to the return periods of drought events.
Overall, results are in agreement with other studies applied to Portugal and the Iberian Peninsula despite differences in the methodological approaches. Further studies to improve the understanding of teleconnections between drought indices and large-scale atmospheric circulation indices for Portugal and the Mediterranean are being developed with the aim of improving the predictability of droughts and supporting related risk management. 


\section{Appendix A}

Table A1. Frequency of the cycles (\%) relative to the number of series included in each cluster (just the significant cycles of the periodograms).

\begin{tabular}{|c|c|c|c|c|c|c|c|c|c|c|c|c|c|c|}
\hline Period & 33.0 & 22.0 & 16.5 & 9.4 & 6.6 & 6.0 & 5.5 & 4.7 & 4.4 & 3.3 & 3.1 & 2.8 & 2.6 & 2.0 \\
\hline \multicolumn{15}{|l|}{ Jan } \\
\hline Cluster 1 & $6.3 \%$ & $3.1 \%$ & $3.1 \%$ & $0.0 \%$ & $0.0 \%$ & $87.5 \%$ & $0.0 \%$ & $37.5 \%$ & $28.1 \%$ & $0.0 \%$ & $0.0 \%$ & $0.0 \%$ & $31.3 \%$ & $0.0 \%$ \\
\hline Cluster 2 & $20.0 \%$ & $0.0 \%$ & $0.0 \%$ & $20.0 \%$ & $0.0 \%$ & $83.3 \%$ & $0.0 \%$ & $0.0 \%$ & $3.3 \%$ & $0.0 \%$ & $0.0 \%$ & $0.0 \%$ & $33.3 \%$ & $3.3 \%$ \\
\hline Cluster 3 & $25.0 \%$ & $0.0 \%$ & $0.0 \%$ & $66.7 \%$ & $50.0 \%$ & $83.3 \%$ & $0.0 \%$ & $0.0 \%$ & $0.0 \%$ & $0.0 \%$ & $8.3 \%$ & $0.0 \%$ & $16.7 \%$ & $16.7 \%$ \\
\hline \multicolumn{15}{|l|}{ Feb } \\
\hline Cluster 1 & $6.3 \%$ & $3.1 \%$ & $3.1 \%$ & $0.0 \%$ & $0.0 \%$ & $78.1 \%$ & $0.0 \%$ & $6.3 \%$ & $0.0 \%$ & $0.0 \%$ & $21.9 \%$ & $0.0 \%$ & $12.5 \%$ & $0.0 \%$ \\
\hline Cluster 2 & $20.0 \%$ & $0.0 \%$ & $0.0 \%$ & $0.0 \%$ & $0.0 \%$ & $70.0 \%$ & $0.0 \%$ & $0.0 \%$ & $0.0 \%$ & $0.0 \%$ & $46.7 \%$ & $0.0 \%$ & $40.0 \%$ & $0.0 \%$ \\
\hline Cluster 3 & $25.0 \%$ & $0.0 \%$ & $0.0 \%$ & $16.7 \%$ & $41.7 \%$ & $83.3 \%$ & $0.0 \%$ & $0.0 \%$ & $0.0 \%$ & $0.0 \%$ & $100.0 \%$ & $0.0 \%$ & $16.7 \%$ & $8.3 \%$ \\
\hline \multicolumn{15}{|l|}{ Mar } \\
\hline Cluster 1 & $3.1 \%$ & $3.1 \%$ & $3.1 \%$ & $0.0 \%$ & $0.0 \%$ & $46.9 \%$ & $3.1 \%$ & $3.1 \%$ & $3.1 \%$ & $0.0 \%$ & $34.4 \%$ & $0.0 \%$ & $84.4 \%$ & $0.0 \%$ \\
\hline Cluster 2 & $10.0 \%$ & $0.0 \%$ & $0.0 \%$ & $0.0 \%$ & $0.0 \%$ & $63.3 \%$ & $26.7 \%$ & $0.0 \%$ & $0.0 \%$ & $0.0 \%$ & $30.0 \%$ & $0.0 \%$ & $80.0 \%$ & $0.0 \%$ \\
\hline Cluster 3 & $25.0 \%$ & $0.0 \%$ & $0.0 \%$ & $16.7 \%$ & $8.3 \%$ & $66.7 \%$ & $25.0 \%$ & $0.0 \%$ & $0.0 \%$ & $0.0 \%$ & $58.3 \%$ & $0.0 \%$ & $25.0 \%$ & $16.7 \%$ \\
\hline \multicolumn{15}{|l|}{ Apr } \\
\hline Cluster 1 & $3.1 \%$ & $3.1 \%$ & $6.3 \%$ & $0.0 \%$ & $0.0 \%$ & $37.5 \%$ & $3.1 \%$ & $3.1 \%$ & $6.3 \%$ & $0.0 \%$ & $12.5 \%$ & $0.0 \%$ & $78.1 \%$ & $0.0 \%$ \\
\hline Cluster 2 & $13.3 \%$ & $0.0 \%$ & $0.0 \%$ & $0.0 \%$ & $0.0 \%$ & $60.0 \%$ & $36.7 \%$ & $3.3 \%$ & $0.0 \%$ & $0.0 \%$ & $43.3 \%$ & $0.0 \%$ & $50.0 \%$ & $3.3 \%$ \\
\hline Cluster 3 & $25.0 \%$ & $0.0 \%$ & $0.0 \%$ & $33.3 \%$ & $8.3 \%$ & $66.7 \%$ & $25.0 \%$ & $0.0 \%$ & $0.0 \%$ & $16.7 \%$ & $58.3 \%$ & $0.0 \%$ & $8.3 \%$ & $33.3 \%$ \\
\hline \multicolumn{15}{|l|}{ May } \\
\hline Cluster 1 & $3.1 \%$ & $3.1 \%$ & $6.3 \%$ & $0.0 \%$ & $0.0 \%$ & $12.5 \%$ & $3.1 \%$ & $9.4 \%$ & $15.6 \%$ & $0.0 \%$ & $12.5 \%$ & $0.0 \%$ & $84.4 \%$ & $0.0 \%$ \\
\hline Cluster 2 & $13.3 \%$ & $0.0 \%$ & $0.0 \%$ & $0.0 \%$ & $0.0 \%$ & $40.0 \%$ & $10.0 \%$ & $6.7 \%$ & $0.0 \%$ & $0.0 \%$ & $36.7 \%$ & $0.0 \%$ & $26.7 \%$ & $10.0 \%$ \\
\hline Cluster 3 & $16.7 \%$ & $0.0 \%$ & $0.0 \%$ & $16.7 \%$ & $8.3 \%$ & $50.0 \%$ & $16.7 \%$ & $0.0 \%$ & $0.0 \%$ & $8.3 \%$ & $41.7 \%$ & $0.0 \%$ & $16.7 \%$ & $75.0 \%$ \\
\hline \multicolumn{15}{|l|}{ Jun } \\
\hline Cluster 1 & $3.1 \%$ & $3.1 \%$ & $6.3 \%$ & $0.0 \%$ & $0.0 \%$ & $12.5 \%$ & $3.1 \%$ & $12.5 \%$ & $15.6 \%$ & $0.0 \%$ & $0.0 \%$ & $0.0 \%$ & $84.4 \%$ & $0.0 \%$ \\
\hline Cluster 2 & $10.0 \%$ & $0.0 \%$ & $0.0 \%$ & $3.3 \%$ & $0.0 \%$ & $30.0 \%$ & $16.7 \%$ & $0.0 \%$ & $0.0 \%$ & $0.0 \%$ & $46.7 \%$ & $0.0 \%$ & $23.3 \%$ & $16.7 \%$ \\
\hline Cluster 3 & $16.7 \%$ & $0.0 \%$ & $0.0 \%$ & $16.7 \%$ & $8.3 \%$ & $41.7 \%$ & $16.7 \%$ & $0.0 \%$ & $0.0 \%$ & $8.3 \%$ & $41.7 \%$ & $0.0 \%$ & $0.0 \%$ & $83.3 \%$ \\
\hline \multicolumn{15}{|l|}{ Jul } \\
\hline Cluster 1 & $3.1 \%$ & $3.1 \%$ & $6.3 \%$ & $0.0 \%$ & $0.0 \%$ & $12.5 \%$ & $3.1 \%$ & $3.1 \%$ & $18.8 \%$ & $0.0 \%$ & $0.0 \%$ & $0.0 \%$ & $84.4 \%$ & $0.0 \%$ \\
\hline Cluster 2 & $10.0 \%$ & $0.0 \%$ & $0.0 \%$ & $3.3 \%$ & $0.0 \%$ & $23.3 \%$ & $10.0 \%$ & $0.0 \%$ & $0.0 \%$ & $0.0 \%$ & $46.7 \%$ & $0.0 \%$ & $30.0 \%$ & $16.7 \%$ \\
\hline Cluster 3 & $16.7 \%$ & $0.0 \%$ & $0.0 \%$ & $16.7 \%$ & $8.3 \%$ & $41.7 \%$ & $16.7 \%$ & $0.0 \%$ & $0.0 \%$ & $16.7 \%$ & $50.0 \%$ & $0.0 \%$ & $0.0 \%$ & $83.3 \%$ \\
\hline \multicolumn{15}{|l|}{ Aug } \\
\hline Cluster 1 & $3.1 \%$ & $3.1 \%$ & $6.3 \%$ & $0.0 \%$ & $0.0 \%$ & $9.4 \%$ & $0.0 \%$ & $6.3 \%$ & $18.8 \%$ & $0.0 \%$ & $9.4 \%$ & $0.0 \%$ & $68.8 \%$ & $0.0 \%$ \\
\hline Cluster 2 & $10.0 \%$ & $0.0 \%$ & $0.0 \%$ & $3.3 \%$ & $0.0 \%$ & $16.7 \%$ & $6.7 \%$ & $3.3 \%$ & $0.0 \%$ & $0.0 \%$ & $46.7 \%$ & $0.0 \%$ & $20.0 \%$ & $20.0 \%$ \\
\hline Cluster 3 & $16.7 \%$ & $0.0 \%$ & $0.0 \%$ & $16.7 \%$ & $8.3 \%$ & $33.3 \%$ & $16.7 \%$ & $0.0 \%$ & $0.0 \%$ & $8.3 \%$ & $50.0 \%$ & $0.0 \%$ & $0.0 \%$ & $83.3 \%$ \\
\hline \multicolumn{15}{|l|}{ Sep } \\
\hline Cluster 1 & $6.3 \%$ & $3.1 \%$ & $6.3 \%$ & $0.0 \%$ & $0.0 \%$ & $15.6 \%$ & $0.0 \%$ & $15.6 \%$ & $15.6 \%$ & $0.0 \%$ & $0.0 \%$ & $0.0 \%$ & $96.9 \%$ & $0.0 \%$ \\
\hline Cluster 2 & $13.3 \%$ & $0.0 \%$ & $0.0 \%$ & $10.0 \%$ & $0.0 \%$ & $36.7 \%$ & $23.3 \%$ & $0.0 \%$ & $0.0 \%$ & $0.0 \%$ & $23.3 \%$ & $0.0 \%$ & $23.3 \%$ & $13.3 \%$ \\
\hline Cluster 3 & $16.7 \%$ & $0.0 \%$ & $0.0 \%$ & $25.0 \%$ & $0.0 \%$ & $41.7 \%$ & $25.0 \%$ & $0.0 \%$ & $0.0 \%$ & $0.0 \%$ & $33.3 \%$ & $8.3 \%$ & $0.0 \%$ & $83.3 \%$ \\
\hline \multicolumn{15}{|l|}{ Oct } \\
\hline Cluster 1 & $3.1 \%$ & $3.1 \%$ & $3.1 \%$ & $0.0 \%$ & $0.0 \%$ & $15.6 \%$ & $0.0 \%$ & $40.6 \%$ & $12.5 \%$ & $0.0 \%$ & $0.0 \%$ & $3.1 \%$ & $90.6 \%$ & $0.0 \%$ \\
\hline Cluster 2 & $13.3 \%$ & $0.0 \%$ & $0.0 \%$ & $13.3 \%$ & $0.0 \%$ & $43.3 \%$ & $10.0 \%$ & $43.3 \%$ & $3.3 \%$ & $0.0 \%$ & $20.0 \%$ & $10.0 \%$ & $13.3 \%$ & $0.0 \%$ \\
\hline Cluster 3 & $16.7 \%$ & $0.0 \%$ & $0.0 \%$ & $16.7 \%$ & $0.0 \%$ & $75.0 \%$ & $8.3 \%$ & $33.3 \%$ & $0.0 \%$ & $0.0 \%$ & $8.3 \%$ & $8.3 \%$ & $0.0 \%$ & $8.3 \%$ \\
\hline \multicolumn{15}{|l|}{ Nov } \\
\hline Cluster 1 & $6.3 \%$ & $3.1 \%$ & $6.3 \%$ & $0.0 \%$ & $0.0 \%$ & $50.0 \%$ & $0.0 \%$ & $71.9 \%$ & $0.0 \%$ & $0.0 \%$ & $3.1 \%$ & $12.5 \%$ & $6.3 \%$ & $0.0 \%$ \\
\hline Cluster 2 & $16.7 \%$ & $0.0 \%$ & $0.0 \%$ & $20.0 \%$ & $0.0 \%$ & $66.7 \%$ & $0.0 \%$ & $66.7 \%$ & $0.0 \%$ & $13.3 \%$ & $16.7 \%$ & $3.3 \%$ & $0.0 \%$ & $0.0 \%$ \\
\hline Cluster 3 & $16.7 \%$ & $0.0 \%$ & $0.0 \%$ & $41.7 \%$ & $0.0 \%$ & $91.7 \%$ & $0.0 \%$ & $91.7 \%$ & $0.0 \%$ & $16.7 \%$ & $0.0 \%$ & $0.0 \%$ & $0.0 \%$ & $16.7 \%$ \\
\hline \multicolumn{15}{|l|}{ Dec } \\
\hline Cluster 1 & $9.4 \%$ & $6.3 \%$ & $3.1 \%$ & $6.3 \%$ & $0.0 \%$ & $84.4 \%$ & $0.0 \%$ & $40.6 \%$ & $9.4 \%$ & $0.0 \%$ & $0.0 \%$ & $0.0 \%$ & $3.1 \%$ & $0.0 \%$ \\
\hline Cluster 2 & $16.7 \%$ & $0.0 \%$ & $0.0 \%$ & $50.0 \%$ & $0.0 \%$ & $90.0 \%$ & $0.0 \%$ & $0.0 \%$ & $0.0 \%$ & $0.0 \%$ & $0.0 \%$ & $0.0 \%$ & $0.0 \%$ & $16.7 \%$ \\
\hline Cluster 3 & $16.7 \%$ & $0.0 \%$ & $0.0 \%$ & $100.0 \%$ & $50.0 \%$ & $91.7 \%$ & $0.0 \%$ & $0.0 \%$ & $0.0 \%$ & $16.7 \%$ & $0.0 \%$ & $0.0 \%$ & $0.0 \%$ & $25.0 \%$ \\
\hline
\end{tabular}


Acknowledgements. This work was partially supported by the Fundação para a Ci\%ncia e a Tecnologia (Portuguese Foundation for Science and Technology) through the project UID/MAT/00297/2013 (Centro de Matemática e Aplicações) and the project PTDC/GEO-MET/3476/2012 (Predictability assessment and hybridization of seasonal drought forecasts in Western Europe), and the scholarship SFRH/BD/92880/2013 provided by FCT to D. Martins is acknowledged.

Edited by: M.-C. Llasat

Reviewed by: three anonymous referees

\section{References}

Bierkens, M. F. P. and Van Beek, L. P. H.: Seasonal predictability of European discharge: NAO and hydrological response time, J. Hydrometeorol., 10, 953-968, 2009.

Bloomfield, P.: Fourier Analysis of Time Series. An Introduction, J. Wiley \& Sons, New York, 2000.

Bordi, I., Fraedrich, K., Gerstengarbe, F.-W., Werner, P. C., and Sutera, A.: Potential predictability of dry and wet periods: Sicily and Elbe-Basin (Germany), Theor. Appl. Climatol., 77, 125-138, 2004a.

Bordi, I., Fraedrich, K., Jiang, J. M., and Sutera, A.: Spatiotemporal variability of dry and wet periods in eastern China, Theor. Appl. Climatol., 79, 81-91, 2004b.

Bordi, I., Fraedrich, K., Petitta, M., and Sutera, A.: Large-scale assessment of drought variability based on NCEP/NCAR and ERA-40 re-analyses, Water Resour. Manage., 20, 899-915, 2006.

Chattopadhyay, S. and Chattopadhyay, G.: The possible association between summer monsoon rainfall in India and sunspot numbers, Int. J. Remote Sens., 32, 891-907, 2011.

Fisher, R. A.: Tests of significance in harmonic analysis, Proc. R. Soc. Lond. A, 125, 54-59, doi:10.1098/rspa.1929.0151, 1929.

Gómiz-Fortis, S. R., Hidalgo-Muñoz, J. M., Argüeso, D., EstebanParra, M. J., and Castro-Díez, Y.: Spatio-temporal variability in Ebro river basin (NE Spain): Global SST as potential source of predictability on decadal time scales, J. Hydrol., 409, 759-775, 2011.

Guttman, N. B.: Accepting the standardized precipitation index: A calculation algorithm, J. Am. Water Resour. Assoc., 35, 311322, 1999.

Hathaway, D. H.: The solar cycle. Living Rev, Solar Phys. 7, available at: http://www.livingreviews.org/lrsp-2010-1 (last access: October 2013), 2010.

Helsel, D. R. and Hirsch, R. M.: Statistical Methods in Water Resources. Elsevier, Amsterdam, 522 pp., 1992.

Hirsch, R. M.: A comparison of four streamflow record extension techniques, Water Resour. Res., 18, 1081-1088, 1982.

Kücük, M., Kahya, E., Cengiz, T. M., and Karaca M.: North Atlantic Oscillation influences on Turkish lake levels, Hydrol. Process., 23, 893-906, 2009.

Labat, D.: Oscillations in land surface hydrological cycle, Earth Planet. Sci. Lett., 242, 143-154, 2006.

Li, B., Su, H., Chen, F., Li, S., Tian, J., Qin, Y., Zhang, R., Chen, S., Yang, Y., and Rong, Y.: The changing pattern of droughts in the
Lancang River Basin during 1960-2005, Theor. Appl. Climatol., 111, 401-415, 2013.

Liang, L., Li, L., and Liu, Q.: Precipitation variability in Northeast China from 1961 to 2008, J. Hydrol., 404, 67-76, 2011.

Liu, Z., Zhou, P., Zhang, F., Liu, X., and Chen, G.: Spatiotemporal characteristics of dryness/wetness conditions across Qinghai Province, Northwest China, Agr. Forest. Meteorol., 182, 101108, 2013.

Lucero, O. A. and Rodríguez, N. C.: Spatial organization in Europe of decadal and interdecadal fluctuations in annual rainfall, Int. J. Climatol., 22, 805-820, 2002.

Martins, D. S., Raziei, T., Paulo, A. A., and Pereira, L. S.: Spatial and temporal variability of precipitation and drought in Portugal, Nat. Hazards Earth Syst. Sci., 12, 1493-1501, doi:10.5194/nhess-12-1493-2012, 2012.

Mazzarella, A. and Palumbo, F.: Rainfall fluctuations over Italy and their association with solar activity, Theor. Appl. Climatol., 45, 201-207, 1992.

McKee, T. B., Doesken, N. J., and Kleist, J.: The relationship of drought frequency and duration to time scales, in: 8th Conference on Applied Climatology, Am. Meteorol. Soc. Boston, 179-184, 1993.

McKee, T. B., Doesken, N. J., and Kleist, J.: Drought monitoring with multiple time scales, in: 9th Conference on Applied Climatology, Am. Meteor. Soc., Boston, 233-236, 1995.

Mendoza, B., Velasco, V. and Jáuregui, E.: A study of historical droughts in Southeastern Mexico, J. Climate, 19, 2916-2934, 2006.

Mishra, A. K. and Singh, V. P.: A review of drought concepts, J. Hydrol., 391, 202-216, 2010.

Mitra, K., Mukherji, S., and Dutta, S. N.: Some indications of 18.6 year LUNI-Solar and 10-11 year solar cycles in rainfall in NorthWest India, the plains of Uttar Pradesh and North-Central India, Int. J. Climatol., 11, 645-652, 1991.

Moreira, E. E., Paulo, A. A. Pereira, L. S., and Mexia, J. T.: Analysis of SPI drought class transitions using loglinear models, J. Hydrol., 331, 349-359, 2006.

Moreira, E. E., Mexia, J. T., and Pereira, L. S.: Are drought occurrence and severity aggravating? A study on SPI drought class transitions using log-linear models and ANOVA-like inference, Hydrol. Earth Syst. Sci., 16, 3011-3028, doi:10.5194/hess-163011-2012, 2012.

North, G. R., Bell, T. L., and Cahalan, R. F.: Sampling errors in the estimation of empirical orthogonal functions, Mon. Weather Rev., 110, 699-706, 1982.

Nowroozi, A. A.: Table for Fisher's test of significance in harmonic analysis, Geophys. J. Int., 12, 517-520, 1967.

Paulo, A. A. and Pereira, L. S.: Drought concepts and characterization: comparing drought indices applied at local and regional scales, Water Int., 31, 37-49, 2006.

Paulo, A. A., Rosa, R. D., and Pereira, L. S.: Climate trends and behaviour of drought indices based on precipitation and evapotranspiration in Portugal, Nat. Hazards Earth Syst. Sci., 12, 14811491, doi:10.5194/nhess-12-1481-2012, 2012.

Piervitali, E. and Colacino, M.: Evidence of drought in western Sicily during the period 1565-1915 from liturgical offices, Clim. Change, 49, 225-238, 2001. 
Pires, C. A. and Perdigão, R. A. P.: Non-gaussianity and asymmetry of the winter monthly precipitation estimation from the NAO, Mon. Weather Rev., 135, 430-448, 2007.

Pollock, D. S. G.: A Handbook of Time-Series Analysis. Signal Processing and Dynamics, Academic Press, London, 1999.

Polonskii, A. B., Basharin, D. V., Voskresenskaya, E. N., and Worley, S.: North Atlantic Oscillation: description, mechanisms, and influence on the Eurasian climate, Phys. Oceanogr., 14, 96-113, 2004.

Prokoph, A., Adamowski, J., and Adamowski, K.: Influence of the 11-year solar cycle on annual streamflow maxima in Southern Canada, J. Hydrol., 442, 55-62, 2012.

Raziei, T., Saghafian, B., Paulo, A. A., Pereira, L. S., and Bordi, I.: Spatial patterns and temporal variability of drought in Western Iran, Water Res. Manage., 29, 439-455, 2009.

Raziei, T., Martins, D., Bordi, I., Santos, J., Portela, M., Pereira, L., and Sutera, A.: SPI Modes of Drought Spatial and Temporal Variability in Portugal: Comparing Observations, PT02 and GPCC Gridded Datasets, Water Resour. Manage., 29, 487-504, doi:10.1007/s11269-014-0690-3, 2014.

Richman, M. B.: Rotation of principal components, J. Climatol. 6, 293-335, 1986.

Rodrigo, F. S., Esteban-Parra, M. J., Pozo-Vazques, D., and CastroDiez, Y.: Rainfall variability in southern Spain on decadal to centennial time scales, Int. J. Climatol., 20, 721-732, 2000.

Rodríguez-Puebla, C., Encinas, A. H., and Sáenz, J.: Winter precipitation over the Iberian peninsula and its relationship to circulation indices, Hydrol. Earth Syst. Sci., 5, 233-244, doi:10.5194/hess-5-233-2001, 2001.

Rosa, R., Paulo, A., Matias, P., Espírito Santo, M., and Pires, C.: Tratamento da qualidade das séries de dados climáticos quanto a homogeneidade, aleatoriedade e tendência e completagem de séries de dados, in: Gestão do Risco em Secas, edited by: Pereira, L. S., Mexia, J. T., and Pires, C. A. L., Métodos, Tecnologias e Desafios, Edições Colibri, CEER, 119-139, 2010.

Santos, J. A., Corte-Real, J., and Leite, S. M.: Weather regimes and their connection to the winter rainfall in Portugal, Int. J. Climatol., 25, 33-50, 2005.

Santos, J. A., Corte-Real, J., and Leite, S.: Atmospheric large-scale dynamics during the 2004/2005 winter drought in Portugal, Int. J. Climatol., 27, 571-586, 2007.

Santos, J. A., Andrade, C., Corte-Real, J., and Leite, S.: The role of large-scale eddies in the occurrence of winter precipitation deficits in Portugal, Int. J. Climatol., 29, 1493-1507, 2009.
Santos, J. F., Pulido-Calvo, I., and Portela, M.: Spatial and temporal variability of droughts in Portugal, Water Resour. Res., 46, W03503, doi:10.1029/2009WR008071, 2010.

Scargle, J. D.: Studies in astronomical time series, II. Sta tistical aspects of spectral analysis of unevenly spaced data, Astrophys. J., Part 1, 263, 835-853, 1982.

Sharma, S.: Applied Multivariate Techniques, John Wiley \& Sons, 512 pp., 1996.

Sousa, P. M., Trigo, R. M., Aizpurua, P., Nieto, R., Gimeno, L., and Garcia-Herrera, R.: Trends and extremes of drought indices throughout the 20th century in the Mediterranean, Nat. Hazards Earth Syst. Sci., 11, 33-51, doi:10.5194/nhess-11-33-2011, 2011.

Steinemann, A. C., Hayes, M. J., and Cavalcanti, L. F. N.: Drought indicators and triggers, in: Drought and Water Crises, edited by: Wilhite, D. A., CRC Press, Boca Raton, 71-92, 2005.

Telesca, L., Vicente-Serrano, S. M., and López-Moreno, J. I.: Power spectral characteristics of drought indices in the Ebro river basin at different temporal scales, Stoch. Environ. Res. Risk Assess., 27, 1155-1170, 2013.

Trigo, R. M., D., Osborn, T. J., and Corte-Real, J. M.: The North Atlantic Oscillation influence on Europe: climate impacts and associated physical mechanisms, Clim. Res., 20, 9-17, 2002.

Trigo, R. M., Pozo-Vázquez, D., Osborn, T. J., Castro-Díez, Y., Gámiz-Fortis, S., and Esteban-Parra, M. J.: North Atlantic Oscillation influence on precipitation, river flow and water resources in the Iberian Peninsula, Int. J. Climatol., 24, 925-944, 2004.

Tsiropoula, G.: Signatures of solar activity variability in meteorological parameters, J. Atmos. Solar-Terrest. Phys., 65, 469-482, 2003.

Vicente-Serrano, S. M.: Differences in spatial patterns of drought on different time scales: An analysis of the Iberian Peninsula, Water Resour. Manage., 20, 37-60, 2006.

Vogel, R. M. and Stedinger, J. R.: Minimum variance streamflow record augmentation procedures, Water Resour. Res., 21, 715723, 1985.

Wilhite, D. A. and Buchanan-Smith, M.: Drought as hazard: Understanding the natural and social context, in: Drought and Water Crises, edited by: Wilhite, D. A., CRC Press, Boca Raton, 3-29, 2005.

Yadava, M. G. and Ramesh, R.: Significant longer-term periodicities in the proxy record of the Indian monsoon rainfall, New Astronomy, 12, 544-555, 2007. 